\title{
Cine y profesionalismo médico: una reflexión ilustrada con cuatro películas de Steven Spielberg
}

\author{
Pablo GONZÁLEZ BLASCO1, Graziela MORETO² \\ ${ }^{1}$ Director Científico de SOBRAMFA- Educação Médica e Humanismo. ${ }^{2}$ Directora de Programas de Formación de SOBRAMFA- Educação Médica e Humanismo (Brasil). \\ Autor para correspondencia: Pablo González Blasco. Correo electrónico: www.sobramfa.com.br \\ Recibido el 14 de mayo de 2018; aceptado el 11 de junio de 2018.
}

Cómo citar este artículo: González Blasco P, Moreto G. Cine y profesionalismo médico: una reflexión ilustrada con cuatro películas de Steven Spielberg. Rev Med Cine [Internet] 2019;15(1): 25-31.

DOI: https://dx.doi.org/10.14201/rmc.20245

\begin{abstract}
Resumen
Vivimos en una era donde los resultados, directrices y ensayos clínicos están a la vanguardia de la formación médica. La complejidad viene principalmente de pacientes, no de las enfermedades. Mientras que el conocimiento técnico ayuda en la solución de problemas basados en la enfermedad, el paciente afectado por estas enfermedades sigue siendo un verdadero desafío para el médico en ejercicio. Las películas proporcionan una forma de aprendizaje significativo: son utilizadas como ejemplos para resaltar dilemas morales, ayudan a ilustrar los temas "intangibles", difíciles de enseñar y evaluar: ética, empatía, compasión y profesionalismo. En la base de todas estas posibilidades de aprendizaje se requiere promover la reflexión. Presentamos aquí una reflexión sobre cine y educación médica, ilustrada con cuatro películas conocidas de Spielberg: Amistad (Medicina Centrada en el Paciente, Empatía, Individualidad), La Lista de Schindler (Compromiso, honradez. ¿Cuáles son los límites para servir?), El rescate del Soldado Ryan (Práctica Reflexiva, Hábito vital reflexivo), Puente de los Espías (Ética, integridad. Ir más lejos de los deberes prescritos). Aunque Spielberg trata frecuentemente temas relativos a la imaginación y de ciencia ficción, el factor humano es probablemente el mensaje más profundo de sus películas: una notable contribución para educar el ser humano.
\end{abstract}

Palabras clave: profesionalismo, cine y educación médica, práctica reflexiva, humanismo médico, Spielberg.

\section{Cinema and medical professionalism: A reflection illustrated with 4 Steven Spielberg's movies}

\begin{abstract}
Summary
We live in an era where outcomes, guidelines, and clinical trials are at the forefront of medical training. Complexity comes mostly from patients, not from diseases. While technical knowledge helps in solving disease-based problems, the patient affected by these diseases remains a real challenge for the practicing doctor. Films provide a multilayered nucleus form which significant learning can take place: they are used as examples to highlight moral dilemmas, and to envision those "intangibles" topics, difficult to teach and to assess, in which ethics, empathy, compassion and professionalism are included. But at the basis of all these learning possibilities reflection is required. In this article we promote a reflection on medical education illustrated with four well known Spielberg's movies: Amistad (Patient Centered Medicine, Empathy, looking at the individual), Schindler 's List (Commitment, where are the limits for serving?), Saving Private Ryan (Reflective Practice. Building a reflective habit for life), Bridge of Spies (Ethics and integrity. Going beyond your duties). Although Spielberg deals frequently with imagination and science fiction, the human factor is probably the best deep message of his movies and represent an outstanding contribution to the education of the human being.
\end{abstract}

Keywords: Professionalism, Movies and Medical Education, Reflective Practice, Medical Humanism, Spielberg.

Los autores declaran que el artículo es original y que no ha sido publicado previamente. 


\section{Técnica, humanismo y dilemas éticos}

Es común observar entre los médicos hoy en día, una razonable formación técnica que conviviendo con una postura humanística deficiente decanta en insuficiencia ética y en falta de profesionalismo. La formación ética de Médicos y Estudiantes de medicina está intrínsecamente relacionada con la dimensión humanística de la educación médica. Enseñar ética y promover el humanismo requiere soluciones innovadoras teniendo en cuenta que la enseñanza teórica se muestra insuficiente. Promover las actitudes éticas supone más que ofrecer conceptos teóricos, reglas de conducta o entrenar las reacciones; implica promover la reflexión -hacer pensar, verdadero núcleo del proceso que humaniza - para facilitar al joven profesional el descubrimiento de sí mismo, permitiéndole extraer de su interior un compromiso vocacional perdurable.

Vivimos en una era donde los resultados, directrices y ensayos clínicos están a la vanguardia de la formación médica. La complejidad viene principalmente de pacientes, no de las enfermedades. Mientras que el conocimiento técnico ayuda en la solución de problemas basados en la enfermedad, el paciente afectado por estas enfermedades sigue siendo un verdadero desafío para el médico en ejercicio. Cuidar implica tener una comprensión del ser humano. Cuidar del enfermo supone conocer la enfermedad y conocer al enfermo, es decir, a la persona que la padece. Entre las habilidades que garantizan la calidad de esa relación la empatía ocupa un lugar destacado por ser un camino práctico para incorporar los progresos técnicos y traducirlos en cuidado eficaz de la persona. ¿Es posible enseñar a ser empático? Estudios recientes demuestran el deterioro que la empatía sufre durante los años de formación ${ }^{1}$. Las estrategias educativas estarían dirigidas a prevenir la erosión de la empatía más que a aumentarla².

Los cuestionamientos éticos se presentan con frecuencia envueltos en emociones que no pueden ser ignoradas; hay que contemplarlas y utilizarlas porque son un elemento esencial del proceso formativo. Compartir emociones, ampararlas en discusiones abiertas, descubre caminos para una verdadera construcción afectiva y fomenta la empatía que aproxima a las personas (médicos y pacientes). Las emociones, por sí solas, no son suficientes para educar. Es necesaria la habilidad del docente para conseguir que la emoción se transforme en vivencia, estimule la reflexión y se interiorice. Este proceso es el catalizador que, aprovechando el terreno fértil de la emoción, imprime una huella educativa: se genera la vivencia que es puerta abierta para incorporar actitudes estables y duraderas ${ }^{3}$.

\section{Las humanidades y la educación médica}

Las artes y las humanidades mejoran la comprensión de la condición humana, son recursos útiles cuando se incorporan al proceso educativo porque ayudan en la construcción de una perspectiva humanista del hacer médico. Existen variados proyectos en educación, que cristalizan en líneas de investigación, y tienen como denominador común el postulado de que las artes ayudan a comprender las emociones humanas, las actitudes del estudiante $y$, en último término, ayudan al profesor a cuidar correctamente del alumno. Concretamente, en el campo de la educación médica los recursos humanísticos abarcan el amplio espectro de la condición humana. Literatura y teatro ${ }^{4,5}$, poesía 6 , ópera7 componen el mosaico de posibilidades que los educadores utilizan para ayudar al estudiante a construir su identidad equilibrada, su formación completa. El uso de la literatura, del teatro y de la poesía, son recursos clásicos de la educación humanística del estudiante, pues la emoción que despierta el contacto con los modelos variados del ser humano les ayuda e reflexionar. Mejor que describir los celos es, sin duda, representar Otelo. Y el remordimiento se hace transparente en Crimen y Castigo.

Enseñar a través de la estética -artes y humanidades- estimula la reflexión y facilita el aprendizaje. Las emociones, que anteceden a los conceptos racionales, tienen un papel esencial cuando se pretende enseñar actitudes y comportamiento. Con acierto coloca esta cuestión un estudioso del tema: "La tarea del educador no es precisamente acabar con el error, porque el error es condición inherente a una naturaleza humana imperfecta. En cambio, sí debe conseguir que brille la verdad y será la luz de la verdad la que consiga disipar las tinieblas del error, la mentira y el equívoco. Un educador 'matando' errores no pasa de ser un dialéctico en inminente riesgo de convertirse en sofista (...) Aristóteles afirmó que sus lecciones de ética eran inútiles en quienes no tuvieran la formación apropiada. Se puede entender algo intelectualmente, pero si afectivamente no hay disposición positiva en esa dirección, todo el discurso resultará estéril. Lo que entre por un oído saldrá por el otro"8.

En su ensayo sobre la virtud, Maclntyre nos recuerda que, en la cultura griega, en la medieval y renacentista el medio principal de educación moral era contar historias 9 ; esa es la sustitución posible que salva la imposibilidad de que todos los hombres pasen por la amplia gama de experiencias intensas que el ser humano es capaz de atravesar. Las artes que cuentan historias -teatro, literatura, cine, ópera- tendrían esta función de suplir lo que la mayoría no es capaz de vivir personalmente. $Y$ 
con la experiencia "vivida a través del arte contador de historias" se puede producir lo que Aristóteles denominaba Catarsis. Una catarsis que, si no puede ser vivida por la experiencia, puede ser facilitada por la historia que nos llega en forma de arte.

No es, por tanto, función del arte servir de pasatiempo o diversión, sino provocar sentimientos -alegría, entusiasmo, rechazo, aprobación, condena- para configurar el corazón de las gentes. Este, y no otro, era el papel de la tragedia griega, la provocación de la catarsis, entendida con doble significado. Por un lado, una verdadera limpieza orgánica, como si de un purgante se tratase; por otro, y aquí surge la perspectiva educacional, mediante la catarsis es posible colocar "en su sitio" los sentimientos acumulados -emociones- que la mayoría de las veces se amontonan de modo desordenado en la afectividad.

La ayuda que los clásicos nos brindan para trabajar las emociones, es por demás útil si admitimos que en el universo del estudiante de hoy las emociones son actores principales en el escenario de la educación. Educar, por tanto, tendrá que contemplar las emociones -nunca ignorarlas- y aprender a aprovecharlas, y a colocarlas en su verdadero lugar, facilitando la catarsis, el libre fluir de las mismas. Compartir emociones, ampararlas en discusiones abiertas, abre caminos para una verdadera reconstrucción afectiva que la cultura actual prácticamente impone. En el moderno contexto cultural se puede afirmar, sin temor a equivocarse, que las emociones son como la puerta de entrada para entender el universo donde el alumno transita, se mueve, y consecuentemente se forma.

La educación de la afectividad puede ser, pues, un atajo de capital importancia en el proceso de aprendizaje. El caso del cine, como veremos después, representa una experiencia educativa innovadora y peculiar, pues las emociones de alumnos y profesores emergen con facilidad delante de un arte que les alcanza porque les es familiar. ¿Es posible utilizar esas emociones acoplándolas a una metodología bien fundamentada para desarrollar la educación de la afectividad?

\section{Emociones y la educación de la afectividad}

Comprender el universo cultural del estudiante es condición necesaria para la buena marcha de cualquier proyecto educacional. Esto es lo que Ortega quería decir cuando advertía que no bastaba saber lo que se dice, sino a quien se está diciendo. $Y$ por eso, al tratar de la Universidad la definía como "la proyección institucional del estudiante". Es decir; lo que a final de cuentas importa no es lo que el profesor enseña, o un saber abstracto, sino lo que realmente se puede enseñar y lo que el estudiante es capaz de aprender ${ }^{10}$.

Sabemos, como fruto de la experiencia, que muchas de las cosas importantes de la vida no se transmiten por argumentación sino a través de un proceso diferente, afectivo, que tiene que ver más con el afecto-amor que se emplee en educar, que con razonamientos especulativos. Partiendo de esta experiencia, Ruiz Retegui11, en su ensayo sobre la belleza, comenta que educar a través de la estética no es pretender anclar en la emoción y en la sensibilidad todo el cuerpo de conceptos necesarios para construir los valores de la persona. Lo que se pretende es provocar la reflexión, condición imprescindible para cualquier intento de construcción de la personalidad. Se puede enseñar técnica, incorporar habilidades sin reflexionar; pero no se pueden adquirir virtudes, modificar actitudes, sin reflexión. Hay que pensar, o mejor, hay que hacer pensar, y para esto sirve la estética, y las emociones que la acompañan. Se trata de establecer un punto de partida, como una pista desde la que se pueda despegar para un aprendizaje más profundo. Empezar por lo que es bonito y estéticamente bello, lo que "nos afecta la emoción" (de ahí la palabra afectividad, lo que me afecta), para después zambullirse en la construcción de valores que además de bonitos sean verdaderos.

La cultura de la emoción está intrínsecamente unida al otro elemento que delinea el universo del estudiante: la imagen, o como Ferrés ${ }^{12}$ define, "una cultura del espectáculo". El estudiante llega hasta el educador anclado en una formación que privilegia la información rápida, el impacto emotivo, la intuición en vez del razonamiento lógico. Predomina una cultura de la prisa; las personas se refugian en la velocidad, son empujadas a vivir el presente, y por la prisa -en palabras de Ferrés"no consiguen frecuentar el pasado". Un contexto cultural de lo fragmentario, de lo rápido y sensorial, que se traduce en actitudes inmediatistas, dinámicas, impacientes. Así es la imagen sensible, y no el concepto lógico, la que asume el protagonismo en la "cultura del espectáculo"; lo sensorial es potenciado porque alcanza directamente al espectador, provocando emociones, sin pasar previamente por la comprensión racional. La recompensa emotiva es directa, diferente de la que se obtiene cuando se "comprende un concepto" y después la comprensión provoca la emoción correspondiente. Con la imagen todo es directo, rápido, como un atajo que despierta la emoción sin que se sepa por qué. Las emociones derivan de los significantes, sin necesidad de entenderse los significados, el contenido conceptual. 
Contemplar este panorama desde una perspectiva educativa se traduce en una serie de advertencias. La primera es aclarar que la realidad que se nos presenta saturada de emoción e imagen sensible- no significa que el razonamiento y la comprensión intelectual no sean ya necesarios para la construcción de los conceptos en el aprendizaje. Continúan siendo tan necesarios como siempre fueron, pero ahora más que nunca queda claro que no son suficientes. Todo indica que frecuentemente habrá que pasar primero por las emociones como una puerta de entrada para posteriores construcciones lógicas y especulativas. El umbral de la sintonía con el estudiante parece estar hoy constituido por emoción e imagen, y quien vive acostumbrado a guiarse por el sentimiento -emociones provocadas por imágenes externas o internas- difícilmente aceptará el razonamiento lógico si la emoción no le facilita el camino.

Pero toda esta libertad que damos al gobierno de las emociones, ¿no nos dejará al sabor del gusto de cada uno? ¿Cómo es posible construir conocimiento sobre la natural oscilación afectiva? Gustave Thibon aborda el tema en un ensayo delicioso sobre el amor humano: "Para el hombre sacudido por la tempestad de la tristeza no es ningún crimen el contradecirse. Esta frase de Sócrates es una de las más humanas que se hayan pronunciado jamás. No se puede recriminar a un infeliz que sea ilógico. La lógica, instrumento perfecto para la administración de las esencias ideales, falla lamentablemente en el hombre concreto, esa mezcla contradictoria de finito y de infinito. $Y$ especialmente en la desgracia, que es la contradicción vivida desde dentro, lo absurdo a lo vivo (...) Se es más fiel no cuando se piensa mejor, sino cuando se siente más profundamente. Esta sensibilidad profunda conecta con las profundidades del espíritu. Lo verdaderamente espiritual tiene más afinidades con lo sensible que con lo intelectual, y se inserta más fácilmente en una emoción corporal auténtica que en una opinión de la razón o en un movimiento apasionado del yo"13.

Este horizonte que se descortina frente al educador requiere del maestro flexibilidad, observación, un continuo repensar su postura y su actuación, que se reflejará en las metodologías educativa empleadas. Porque un educador trabaja con personas, y no sólo con ideas. No se puede partir únicamente de las ideas a priori, sino que es necesario adaptarse a las reacciones que las ideas provocan en el interlocutor. Hay que educar, pues, al compás de la flexibilidad. Un nuevo desafío que tendrá de ser afrontado si se pretende realmente educar. "Si la nueva generación -comenta Ferrés- no consigue convertir las imágenes en pensamiento, es porque el educador no supo primero convertir el pensamiento en imagen"12. Hay, pues, que respetar el ritmo fisiológico de la emotividad. No se puede obligar a nadie a sentir lo que no siente. Se puede, sencillamente, mostrar el gusto, y esperar que el tiempo -y la reflexión sobre lo que se siente, lo que se gusta, en fin, sobre las emociones- vaya perfeccionando el paladar afectivo. Un proceso que Julián Marías denomina, con sabor clásico, Educación Sentimental ${ }^{14}$. Esta sería la función del educador, un verdadero promotor de la cultura, que despierta el deseo de aprender, contagia el entusiasmo por conocer y consigue que el estudiante coloque lo mejor de sus esfuerzos al servicio de su propia formación.

En una cultura del espectáculo -saturada de imágenes, emoción e intuición- lo narrativo también predomina sobre el discurso. Todo se hace historia, ejemplo, que se traduce en imágenes. Un terreno fértil que invita a pensar en el cine como posibilidad adecuada para ayudar en el proceso educativo.

\section{El cine y la educación médica}

Entre los recursos pedagógicos modernos para desarrollar la educación de la afectividad el cine se ofrece como particularmente útil por sintonizar con un universo donde impera una cultura de la emoción y de la imagen. La sensibilidad que el cine despierta, facilita compartir dudas y fragilidades, permite trabajarlas en ambiente apropiado con supervisión docente, y promociona así la madurez afectiva y el consecuente desarrollo de la empatía, incorporando actitudes "difíciles de enseñar por los métodos tradicionales". De este modo se facilita el aprendizaje porque se promueve la reflexión, que es la base del ejercicio filosófico de la profesión médica ${ }^{15}$.

El cine es una forma sensible de lo narrativo. Una forma rápida, de impacto, donde se cuentan historias, y como éste es el contexto cultural donde el estudiante está anclado es natural que la historia que aparece en el celuloide provoque otras historias, ahora de los propios alumnos. Son historias reales de su vida, o ficticias, de otras películas, pero historias al fin y al cabo que tienen que ser contadas, y oídas, y compartidas. Y a través de las historias los estudiantes se reflejan en las películas, pues a través de los conflictos que el cine coloca viven, metafóricamente, sus propios conflictos, y éstos se vuelven transparentes, son aireados en la discusión, aclarados, en busca de ayuda. Una verdadera catarsis provocada por el contacto con el cine ${ }^{16}$.

Las películas proporcionan una forma de aprendizaje significativo, porque ofrecen una miríada de escenas 
y escenarios que pueden ser disecados, criticados y utilizados como ejemplos para resaltar dilemas morales. Promueven el entusiasmo por el aprendizaje, destacan los temas, mejoran la discusión y la reflexión, ya veces, ayudan a ilustrar puntos de enseñanza específicos. En este punto, podemos prever por qué los temas "intangibles", difíciles de enseñar y evaluar, en los que se incluyen la ética, la empatía, la compasión y el compromiso, podrían ser aprobados a través de la metodología de educación cinematográfica ${ }^{17}$.

En la base de todas estas posibilidades se requiere reflexión. Los educadores están de acuerdo en que se requiere peculiar esfuerzo para desarrollar la honestidad emocional en estudiantes de medicina o en residentes, ya sea en términos de sus propias respuestas afectivas, o en términos de llevar en cuenta las emociones de los demás. Cuando los estudiantes experimentan emociones negativas y nada se hace para construir una educación afectiva real, los estudiantes a veces deciden adoptar una posición de distanciamiento emocional, y esto genera actitudes que carecen de profesionalismo ${ }^{18}$. Las películas narrativas pueden proporcionar un valioso acceso a la vida afectiva de los espectadores "iluminando" dilemas que de otro modo podrían ser ignorados o descuidados. Debido a que los personajes retratados en las películas no son "reales", los estudiantes pueden ser más honestos acerca de sus reacciones que si estuvieran discutiendo casos de pacientes reales. Esta honestidad emocional se convierte en un punto de partida para explorar las respuestas emocionales. Educar con el cine es fomentar en el educando el hábito de pensar, y enseñar caminos para una reflexión permanente: un verdadero ejercicio filosófico de la profesión.

\section{El cine de Spielberg: un caso concreto de educación médica}

Algunas escenas procedentes de diversas películas dirigidas por Steven Spielberg se prestan de modo particular para el tema que nos ocupa: vertientes del profesionalismo médico. Son todas escenas populares, de películas conocidas, y ofrecen un escenario agradable para enseñar y discutir acerca de la profesionalidad médica y las actitudes comprendidas en ella. Aunque Spielberg trata frecuentemente temas relativos a la imaginación y de ciencia ficción, el factor humano es probablemente el mejor y más profundo mensaje de sus películas y representa una contribución sobresaliente a la educación del ser humano.

La comunidad académica solicita pruebas de la eficacia de una nueva técnica antes de abogar o incluso apoyar su aplicación generalizada. Lo que podemos decir es que la adquisición de un gusto por la estética a través de películas proporciona una dimensión adicional al aprendizaje médico. Tal vez, en palabras de Pascal, esto tiene algo que ver con esas "razones del corazón, esas razones que nuestra mente no es capaz de entender"

Sugerimos a seguir cuatro películas de este director que pueden ser útiles para abordar el tema del profesionalismo médico.

Amistad (1997). Director: Steven Spielberg. Actores: Djimon Hounsou, Matthew McConaughey, Anthony Hopkins, Morgan Freeman.

Describe un motín de 1839 a bordo de un barco de esclavos que viaja hacia la costa noreste de América. En una escena, un bebé nace de una esclava. Todos los esclavos están encadenados, y el bebé es el único libre (sin cadenas), y lo pasan a través de todo, sosteniendo en sus brazos, como si estuvieran mostrando un trofeo. En otra escena, el abogado negro busca ayuda para defender a los esclavos. Y aquí surge un maravilloso diálogo sobre "enfoque centrado en las personas". No le basta saber que son esclavos para defenderlos; tiene que saber cuál es la historia de cada uno. No me basta el diagnóstico, sino que tengo que saber quién es el paciente con quien estoy tratando. Surgen con facilidad temas como la Medicina Centrada en el Paciente, la Empatía, la individualidad y la dignidad de cada ser humano.

La Lista de Schindler (Schindler 's List)- (1993). Director: Steven Spielberg. Actores: Liam Neeson, Ralph Fiennes, Ben Kingsley.

En la Polonia ocupada por Alemania durante la Segunda Guerra Mundial, Oskar Schindler se preocupa gradualmente por su fuerza de trabajo judía después de presenciar su persecución por los alemanes nazis. Al final de la película, hay una escena notable: los judíos agradecen a Schindler, pero éste se da cuenta de que podría haber hecho más por ellos y sufre con el dolor de su omisión. Surge un gran tema de discusión: Compromiso, honradez. ¿Cuáles son los límites para servir? ¿Hasta dónde tengo que llegar haciendo el bien?

El Rescate del Soldado Ryan (Saving Private Ryan) (1998). Director: Steven Spielberg . Actores: Tom Hanks, Matt Damon, Tom Sizemore. 
Después del desembarque de Normandía, un grupo de soldados de los EEUU va detrás de líneas enemigas para recuperar a un paracaidista cuyos hermanos han muerto en acción. Las escenas finales son notables. El capitán John Miller (que era un profesor en la vida civil), encuentra a James Ryan que se niega a ir a casa. La batalla sucede y el capitán Miller está gravemente herido. Antes de morir, pronuncia la gran frase: "James, gánatelo, haz por merecer". Después de eso, la película se desplaza 40 años más tarde. James Ryan es ya un anciano, y está visitando la tumba de Miller. El monólogo de James Ryan es una maravillosa lección sobre la vida reflexiva. Temas a discutir: Practica Reflexiva. Ejercicio filosófico de la profesión. Crear el hábito reflexivo de por vida.

Puente de los Espías. (Bridge of Spies) (2015). Director: Steven Spielberg. Actores: Tom Hanks, Mark Rylance, Alan Alda.

Durante la Guerra Fría, un abogado estadounidense es reclutado para defender a un espía soviético arrestado en la corte y luego ayudar a la CIA a facilitar el intercambio del espía por un piloto estadounidense. Hay varias escenas que muestran la integridad del abogado y cómo mantiene el secreto profesional. Y la persistencia que muestra en hacer su trabajo, es reconocido y admirado hasta por el espía soviético. Temas como Ética, confidencialidad, integridad. Ir más lejos de los deberes prescritos se brindan fácilmente a la discusión.

\section{A modo de conclusión}

El cine nos aproxima del ámbito afectivo de alumnos y profesores, y conduce a todos los que participan de esta metodología pedagógica a reflexionar sobre las propias actitudes y a revisar sus experiencias de vida. Es un atajo moderno que conduce, bien utilizado, al conocimiento propio, objetivo indispensable para promover una educación personalizada y sólida: una educación para las virtudes que cristaliza en actitudes duraderas.

La utilización pedagógica del Cine sintoniza bien con el gusto que el estudiante tiene por el caso concreto, por la historia de vida, que le proporcionan la posibilidad de integrar los conocimientos adquiridos en la facultad, al tiempo que apoyan su motivación. El paciente concreto, las historias personalizadas son lo que unifica los contenidos educacionales. Este es el fundamento de la moderna enseñanza basada en problemas.
Cuando se trata de abordar cuestiones éticas, el caso concreto es de gran relevancia, porque la duda ética siempre surge en la cuestión puntual y práctica, no en el marco teórico. La educación médica debe contemplar un espacio para discutir esas dudas prácticas que implican en cómo cuidar al enfermo, cómo comunicarse con la familia, convivir con el sufrimiento y la muerte, todo el campo de los cuidados paliativos, sin olvidar el relacionamiento con los colegas de profesión y el trabajo en equipo. Hay poco espacio formal curricular para abrigar estas discusiones, y el cine es un facilitador que puede colaborar con proyectos que se proponen enseñar bioética de modo longitudinal, y amparar al alumno en las dudas que surgen en los variados escenarios de práctica19,20.

Educar con el cine nos sitúa en el ámbito del personalismo educativo, que se impone como condición de eficacia. Es decir: se pueden transmitir objetivamente los conceptos de física cuántica, astronomía o del cáncer gástrico sin atender a los sentimientos de quien aprende. Pero cuando el objetivo es promover actitudes, tomar decisiones éticas, provocar la reflexión y, en definitiva, construir la personalidad -todo eso está contemplado en el concepto de profesionalismo- la enseñanza teórica es insuficiente. Es necesario condimentar esos principios, hacerlos apetitosos y digestivos. Quizá aquí se encuentra el motivo de los fracasos que proporcionan los cursos de "ética al por mayor", y hasta de los códigos de ética: les falta sabor, y les sobran reglas que, por otro lado, son ya conocidas. Los sentimientos y emociones personalizan los principios facilitando su aplicación práctica.

El cine actúa, pues, como verdadero "facilitador" que permite construir y educar en la ética y en los valores con eficacia y fecundidad $Y$ el cine, como método pedagógico ayuda a pensar, provoca la reflexión, que es el objetivo de los educadores que persiguen la excelencia. Son los que avanzan más allá de programas y contenidos, los que se exigen sin que nadie se lo pida, los que saben que para enseñar bien, ellos mismos tienen que ser mejores personas ${ }^{21}$. Porque educar es el resultado de la magnífica simbiosis que acopla la actividad intelectual al arte de esculpir el ser humano 22 .

\section{Referencias}

1. Moreto G, Blasco PG. A Erosão da empatia nos estudantes de Medicina: um desafio educacional. Rev Bras Med. 2012;69(1):12-7

2. Moreto G. Avaliação da empatia de estudantes de medicina em uma universidade na cidade de São Paulo utilizando dois instrumentos. Tese Doutoral em Medicina (Ciências Médicas). São Paulo: Universidade de São Paulo;2015.

3. Blasco PG, Moreto G, Janaudis MA, Benedetto MAC, Altisent R, DelgadoMarroquin MT. Educar las emociones para promover la formación ética. Pers Bioét.2013;17(1):2848. 
4. Shapiro J. Literature and the arts in medical education. Fam Med. 2000;32(3):157-8.

5. Blasco PG. Literature and movies for medical students. Fam Med. 2001;33(6):426-8

6. Whitman N. A poet confronts his own mortality: what a poet can teach medical students and teacher. Fam Med. 2000;32(10):673-4.

7. Blasco PG, Moreto G, Levites MR. Teaching Humanities through opera: Leading Medical Students to Reflective Attitudes. Fam Med. 2005; 37(1):18-20.

8. Sierra, A: La Afectividad. Eslabón perdido de la educación. Pamplona: Eunsa Ediciones Universidad De Navarra; 2008

9. MacIntyre A. Tras la virtud. Barcelona: Crítica; 1987.

10. Ortega y Gasset J. Misión de la universidad y otros ensayos sobre educación y pedagogía. Madrid: Alianza Editorial; 1997.

11. Ruiz Retegui A. Pulchrum: reflexiones sobre la belleza desde la antropología cristiana. Madrid: Rialp; 1999.

12. Ferres J. Educar en una cultura del espectáculo. Barcelona: Paidós; 2000.

13. Thibon G. Una mirada ciega hacia la luz. Barcelona: Belacqua; 2005. p. 192.

14. Marías J. La educación sentimental. Madrid: Alianza Editorial; 1992.

15. Blasco PG. Humanizando a Medicina: Uma Metodologia com o Cinema. Bol. Acad. Paulista de Psicologia 2011;35(88):240-2.

16. Blasco PG. Educação Médica, Medicina de Família e Humanismo: expectativas, dilemas e motivações do estudante de medicina analisadas a partir de discussões sobre produções cinematográficas. Tese Doutoral. Faculdade de Medicina. São Paulo: Universidade de São Paulo;2002.

17. Blasco PG, Moreto G, Roncoletta AFT, Levites MR, Janaudis MA. Using movie clips to Foster learners' reflection: Improving Education in the Affective Domain. Family Medicine 2006; 38(2), 94-6.

18 Shapiro, J. Perspective: Does Medical Education promote professional Alexithymia? A call for attending to the emotions of patients and self in medical training. Acad Med. 2011; 86(3): 326-32.

19. Moreto G, Bariani DB, Pinheiro TRP, Altisent R, Blasco PG. Una Nueva Metodología Docente en Bioetica: Experiencias con la aplicación del Portafolio a Estudiantes de Medicina en Brasil. Pers Bioét. 2008; 12. 2(31): 133-44.
20. Blasco PG, Otálora MSD, Pastushenko J, Altisent R. ¿Cómo enseñar bioética en el pregrado? Reflexiones sobre experiencias docentes. Aten Primaria 2009; 41(2): 103-8.

21. Parker J. Palmer. The Courage to Teach. San Francisco: Jossey-Bass. 1998. 22. Bain K. What the Best College teachers do. Cambridge: Harvard University Press; 2004.
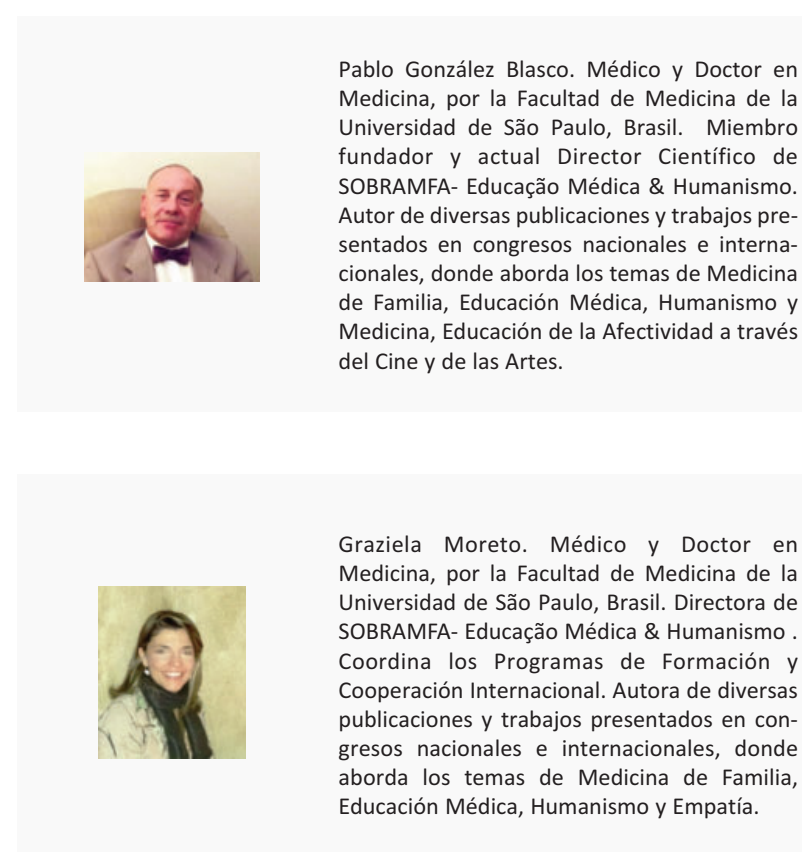